\begin{tabular}{|c|l|}
\hline Title & Community structure of microorganisms associated with reddish-brown iron-rich snow \\
\hline Author(s) & Kojima, Hisaya; Fukuhara, Haruo; Fukui, Manabu \\
\hline Citation & $\begin{array}{l}\text { Systematic and A pplied Microbiology, 32(6), 429-437 } \\
\text { https:/doi.org/40.1016/.syapm.2009.06.003 }\end{array}$ \\
\hline Issue Date & 2009-09 \\
\hline Doc URL & http://hdl.handle.net/2115/39477 \\
\hline Type & article (author version) \\
\hline Additional Information & There are other files related to this item in HUSCAP. Check the above URL. \\
\hline File Information & SAM32-6_p429-437.pdf \\
\hline
\end{tabular}

Instructions for use 
Full length paper

\title{
Community Structure of Microorganisms Associated with Reddish-brown Iron-rich Snow
}

\author{
HISAYA KOJIMA $^{1} *$, HARUO FUKUHARA ${ }^{2}$, and MANABU FUKUI ${ }^{1}$
}

1. The Institute of Low Temperature Science, Hokkaido University, Sapporo, Japan

2. Faculty of Education, Niigata University, Niigata, Japan

Running title: Microorganisms in Reddish Brown Colorings of Snow

*Corresponding author.

The Institute of Low Temperature Science, Hokkaido University, Kita-19, Nishi-8, Kita-ku,

Sapporo 060-0819, Japan

Phone: +81-11-706-5460

Fax: +81-11-706-5460

E-mail: kojimah@pop.lowtem.hokudai.ac.jp 


\section{Abstract}

Reddish-brown colored snow, containing spherical brown particles, is observed in several mires in Japan. In order to characterize this remarkable phenomenon, the microbial community and chemical species in snow were analyzed. A core sample of snow which had colored region was investigated to reveal vertical shifts in physicochemical characteristics and microbial community structure. The abundance of particle peaked within the colored layer, and correlated with amount of reducible Fe(III). Interstitial water of colored layer was enriched with Fe(II), and characterized by reduced concentration of dissolved methane. The bacterial community in the colored region was characterized by higher relative abundance of iron-reducing bacteria and methanotrophs. Aggregates of the brown particles were found as precipitates in snow melt pools, and subjected to cloning analyses targeting several different genes. The majority of bacterial $16 \mathrm{~S}$ rRNA gene clones belonged to the class Betaproteobacteria or the phylum Bacteroidetes. No snow algae were detected in the eukaryotic small subunit rRNA gene clone library. As possible carbon source to sustain the community in snow, involvements of carbon dioxide and methane were investigated by analyzing the genes involved in assimilation of these. In the analyses of genes for ribulose-1,5-biphosphate carboxylase/oxygenase, clones related to sulfur oxidizers were obtained. The analysis on particulate methane monooxygenase genes indicated dominance of Methylobacter species. These results emphasized the uniqueness of this phenomenon, and iron reducers of the genus Geobacter were suggested to be the key organisms that can be investigated to understand the mechanism of this phenomenon.

Key words: Microbial community, Iron, Geobacter, Snow coverage 


\section{Introduction}

In several mires in Japan, reddish-brown colored snow is observed at the time of melting snow [6, 24]. This snow contains abundant spherical brown particles, and they have been regarded as the resting spores of the green algae Hemitoma sp., based solely on the morphological characteristics [6, 24]. Coloration of snow by microbial cells are typically caused by oxygenic phototropic organisms referred to as snow algae [9]. Snow algae accumulate characteristic carotenoids in their cells, which are responsible for the color of the snow. However, the peculiar color of the above-mentioned particles is entirely distinct from that of typical snow algae. In fact, these particles do not accumulate any carotenoids, and their surfaces are abundantly coated with iron [24]. These particles are also accumulated in deeper layers of snow, where no light would be available for photosynthesis [7, 12], e.g., $1 \mathrm{~m}$ under the surface. It has been also reported that diverse invertebrates were found in the colored snow with considerable abundance [6]. In addition, when appearing on the surface, the coloration decreases the albedo of the snow drastically and accelerates snow melting. Despite such potential importance and remarkable uniqueness, this coloring phenomenon itself has not been fully described yet. Especially, involvements of microorganisms in this phenomenon are hardly investigated. In the present study, the outstanding snow coloring phenomenon was characterized with the focus on microorganisms. The microbial community structure was analyzed using small subunit rRNA gene (SSU rDNA) sequencing. In general, snow contains only limited amounts of organic compounds. Therefore, organisms that can assimilate carbon from an external source would play important roles in the community in the accumulated snow. In the present study, organisms assimilating carbon dioxide or methane were examined by analyzing functional genes. These carbon sources are expected to be supplied to 
snowcover from underlying wetlands [2, 3, 15, 22].

\section{Materials and Methods}

Sampling

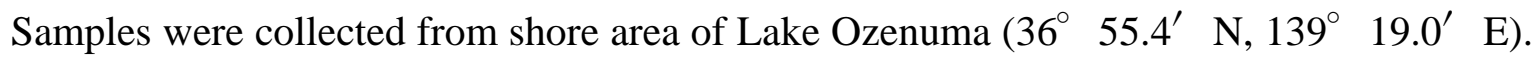

The lake is located $1668 \mathrm{~m}$ above sea level and surrounded by mountains of ca. $2000 \mathrm{~m}$ altitude. In winter, it is covered with snow heavily as deep as $4 \mathrm{~m}$ at the maximum. Seasonal changes in water chemistry have been investigated around the lake, and increase of iron concentration was observed during snow-covered and thaw seasons [17]. The study site was visited repeatedly from 2001 to 2008, in the time of the melting snow (end of April or beginning of May). The coloring phenomenon was observed consistently every year, and samples obtained in 2005 and 2008 were used for the analyses in the present study (Fig. 1a is a photograph taken in May, 2001).

At the sampling time in April 2005, a limited area of the snowfield surface was colored reddish-brown. The surface of colored area sparsely studded with small pools of melted snow water (Fig. 1b). Two types of samples, reddish-brown precipitates in the pools and colored snow from the surface layer, were collected at this sampling. The precipitates mainly consisted of rounded brown particles (Fig. 1c). The colored snow also contained brown particles apparently-indistinguishable from those in the precipitates (Fig. 1f). The samples of colored snow samples were thawed at the site, and particulate substances were collected on the filter with a pore size of $0.22 \mu \mathrm{m}$ (Sterivex filter cartridges; Millipore, Billerica, MA, USA). The materials on the filters were subjected to DNA extraction.

At the sampling time in April 2008, no coloring could be found on the surface of snowfield. Depth of accumulated snow was approximately $160 \mathrm{~cm}$ and it reached to the 
sediment of the lake. With a core sampler (inner diameter $=4 \mathrm{~cm}$ ), a core sample of snow was obtained manually (Fig. 1d, 1e). The 160-cm long snow core was sectioned into five sections (0-20, 20-50, 50-80, 80-120, and 120-160 cm from the surface of sediment), and then thawed on site. The snow melt samples were subjected to particle count, Fe content analysis, and filtration for DNA extraction as described above. A sediment sample was also obtained from the bottom of the core and subjected to DNA based analysis. From the adjacent site, samples of the interstitial water were obtained with an acuate stainless steel pipe. The pipe had an opening near the tip, and it was connected to a syringe by a tube inside the pipe. The pipe was inserted into snow accumulation to set the opening at the desired depths, and water samples were retrieved by pulling up with the syringe. The sampling depths were adjusted to correspond to respective sections of the core sample.

Chemical analysis and particle count

For the samples of interstitial water, dissolved methane concentrations were quantified by using headspace equilibration method. Subsamples $(9 \mathrm{ml})$ of interstitial water from each depth were equilibrated with equal volume of air by vigorous shaking. The methane in the headspace and native air were quantified with a gas chromatograph equipped with a flame ionization detector (GC-2014, Shimadzu, Kyoto). The dissolved methane concentrations were calculated from the mixing ratios in the gaseous phase and temperatures of water after the shaking. Another portion of interstitial water from each depth was mixed with sodium acetate buffer containing 1,10-phenanthroline, immediately after the sampling in order to chelate $\mathrm{Fe}(\mathrm{II})$. The concentrations of chelated Fe(II) were determined photometrically at $510 \mathrm{~nm}$ [18]. Dissolved oxygen concentration was determined by conventional Winkler titration.

Among various forms of Fe compounds, hydroxylamine-reducible Fe was quantified for 
each section of the snow core. Fe(III) in the samples was reduced to Fe(II) by hydroxylamine, under the condition optimized for quantification of microbially reducible Fe(III) [14]. The samples of snow melts were mixed with the solutions of $\mathrm{HCl}$ and hydroxylamine, to obtain final concentration of $0.25 \mathrm{M}$ each. After 1-hour incubation at $22^{\circ} \mathrm{C}, 1,10$-phenanthroline solution was added and then the $\mathrm{pH}$ was raised to approximately 5.5 by adding $\mathrm{NH}_{4} \mathrm{OH}$ solution. The concentration of generated Fe(II) was determined photometrically, after adding the sodium acetate buffer. The reddish-brown particles in the melts of snow were directly counted under a microscope.

\section{DNA extraction}

Before DNA extraction, the precipitate samples were washed 4 times in Tris-ethylenediaminetetraacetic acid (EDTA) buffer. From the washed samples, genomic DNA was extracted by the method described previously with several modifications [23]. Briefly, the washed precipitates were homogenized in Tris-EDTA buffer containing sodium dodecyl sulfate, and then subjected to 3 freeze-thaw cycles. Proteinase K was added into the sample tube and incubated at $37^{\circ} \mathrm{C}$ for $60 \mathrm{~min}$. After the enzymatic digestion, $\mathrm{NaCl}$ and cetyltrimethylammonium bromide solution were added and incubated for $10 \mathrm{~min}$ at $65^{\circ} \mathrm{C}$. Nucleic acid was purified by extraction with chloroform-isoamyl alcohol (24:1, v/v) and phenol-chloroform-isoamyl alcohol (25:24:1, v/v/v). From the obtained aqueous supernatant, DNA was precipitated by the addition of isopropanol and following centrifugation. The resultant pellet was rinsed with $70 \%$ ethanol.

DNA extraction was performed in a similar manner for the snow samples collected on the filter, but the enzymatic digestion was replaced with physical disruption by bead-beating. After the freeze-thaw cycles in Tris-EDTA buffer containing sodium dodecyl sulfate, 
phenol-chloroform-isoamyl alcohol (25:24:1, v/v/v) was added into the tubes. The samples were subjected to bead-beating for $60 \mathrm{~s}$ at $2000 \mathrm{rpm}$, with $0.5 \mathrm{~g}$ of glass beads (equal-weight mixture of $0.1-\mathrm{mm}$ - and $0.05-\mathrm{mm}$-diameter beads). $\mathrm{NaCl}$ and cetyltrimethylammonium bromide solution were added to the aqueous supernatant. The following procedures performed were almost the same as those used for the precipitate samples.

Total DNA from the sample of sediment was isolated with the UltraClean Soil DNA Kit (Mo Bio, Solana Beach, Calif.)

\section{PCR-DGGE of bacterial 16S rDNA}

For denaturing gradient gel electrophoresis (DGGE) analysis, bacterial 16S rDNA fragments were amplified with the primer pair GC341f [16] and 533r [8], using TaKaRa Ex Taq (Takara Bio, Inc., Otsu, Japan). PCR amplification was initiated with 2 min of denaturation at $94^{\circ} \mathrm{C}$. Each thermal cycle comprised $30 \mathrm{~s}$ of denaturation at $94^{\circ} \mathrm{C}, 30 \mathrm{~s}$ of annealing at $45^{\circ} \mathrm{C}$, and $45 \mathrm{~s}$ of elongation at $72^{\circ} \mathrm{C}$. There was a total of 25 cycles. Finally, an additional extension step was carried out at $72^{\circ} \mathrm{C}$ for $10 \mathrm{~min}$. DGGE was performed with a DCode system (Bio-Rad, Hercules, CA, USA) using $1.5 \mathrm{~mm}$ thick 6\% (w/v) polyacrylamide gel (acrylamide:bisacrylamide $=37.5: 1$ ) prepared to contain a $30 \%$ to $70 \%$ gradient of urea and formamide (100\% corresponds to $40 \%$ (v/v) formamide and $7 \mathrm{M}$ urea). Sequence-specific separation was performed by electrophoresis in $0.5 \times$ TAE buffer $(20 \mathrm{mM}$ Tris, $10 \mathrm{mM}$ acetic acid, and $0.5 \mathrm{mM}$ EDTA; $\mathrm{pH}$ 8) at $60^{\circ} \mathrm{C}$ for $820 \mathrm{~min}$ at a constant voltage of $100 \mathrm{~V}$. The resulting bands were visualized by ethidium bromide staining. Major bands were cut from the DGGE gel, and DNA fragments in the gel pieces were amplified with the same primer pair. The resulting amplification products were subjected to DGGE again to confirm formation of single bands at proper positions, and then purified and sequenced. 
Cloning analysis

The fragments of the targeted genes were amplified with the 5 primer pairs from the genomic DNA extracted the precipitate sample. Gene fragments for SSU rRNA were amplified with two domain-specific primer pairs, 27F/1492R for bacteria [13], and E4F/E1628R for eukaryotes [20]. The annealing temperatures for these primer pairs were 45 and $54^{\circ} \mathrm{C}$ respectively, and numbers of PCR cycles were both 25 . Two primer pairs were used to analyze genes for forms I and II of ribulose-1,5-biphosphate carboxylase/oxygenase (RuBisCO), as previously described [4]. The primer pair used for form I was designed to detect green-like group, a major group of RuBisCO which encompasses those from plants, green algae, and Cyanobacteria, as well as from Alfa-, Beta-, and Gammaproteobacteria. The fragments of genes for particulate methane monooxygenase (pmoA) were amplified with the primers A189 and A682 [10], for specific detection of methanotrophs. The obtained amplification products were ligated into the pCR2.1-TOPO vectors (Invitrogen, Carlsbad, CA, USA), which were then transformed into competent TOP10 cells (Invitrogen). From the established clone libraries, 10-50 clones were randomly selected, and the cloned inserts were sequenced. For clones of the eukaryotic SSU rRNA gene, partial sequence was determined for each clone. For the clones of other genes, whole regions of amplification products were sequenced.

Phylogenetic analysis

The program ClustalX [19] was used to align the sequences from 5 clone libraries. Based on the resulting alignment, pairwise genetic distances were calculated by using the MEGA2 program [11] to sort the clones into operational taxonomic units (OTUs). In the analyses of 
SSU rRNA genes, genetic distances were calculated using the Kimura 2-parameter model. The clones were grouped in such a way that distances between clones of the same OTU did not exceed 0.021 in any combination. The sequences of representative clones from the respective OTUs were compared to those in the DDBJ/EMBL/Genbank database by using the online BLAST program located at the NCBI website. Based on results of the analysis, noticeable lineages were selected for further detailed analyses. The sequences of the selected clones were aligned with the related sequences retrieved from the public database, and phylogenetic trees were constructed using the minimum evolution method. The robustness of the obtained trees was assessed with bootstrap tests of 1000 replicates. Peptide sequences were deduced from the nucleotide sequences of the protein-coding genes, and then subjected to further analyses. On the basis of pairwise comparisons, OTUs were defined as exclusive groups of clones in which a certain number of amino acids (98-100\% of available sites) were shared by all combinations of members. Phylogenetic relationships of the OTUs and their relatives were analyzed by constructing minimum evolution trees. For the tree construction, genetic distances were calculated with the Poisson correction.

Nucleotide sequence accession numbers

The nucleotide sequences determined in this study have been assigned the DDBJ/EMBL/GenBank accession numbers AB504905-AB505023 and AB505076-AB505162.

\section{Results}

Vertical profiles of chemical compounds

At the sampling time in 2008, several snow cores were obtained and they all had colored 
region near the sediment surface (Fig. 1d). One of the cores which had obviously colored region ranging from 15 to $55 \mathrm{~cm}$ (depths are expressed as distance from the sediment-snow interface) was selected for the detailed analyses. The core was sectioned into six parts, i.e. sediment, 0-20 cm (slightly colored region), 20-50 cm (most heavily colored region, Fig. 1e), 50-80 cm (including upper boundary of colored region), 80-120 cm, and 120-160 cm. The last two could not be recognized as colored snow with the naked eye. Temperature of the sediment portion was $3.3^{\circ} \mathrm{C}$. The samples of snow contained reddish brown particles, and their abundance peaked at 20-50 cm (Table 1). The upper two layers seemed not to be colored, but they also contained a small number of the particles. The amounts of hydroxylamine-reducible Fe (including Fe(II) oxidized during the sample preparation) were determined for respective layers, and there was significant positive correlation between particle abundance and Fe amount $\left(\mathrm{r}^{2}=0.997, \mathrm{p}<0.001\right)$.

In order to prevent loss of gaseous compounds and oxidization of reduced compounds, interstitial water samples were directly obtained from the accumulation of snow. The concentrations of dissolved methane, Fe(II), and oxygen are summarized in Table 1. The sample of interstitial water from $28 \mathrm{~cm}$, corresponding to heavily colored region, exhibited reddish-brown color. The sample contained abundant Fe(II), and its concentration was nearly 70 times more than those in both adjacent depths. The water sample of this depth was also characterized by reduced concentration of dissolved methane, corresponding to $20-30 \%$ of adjacent depths. Concentration of dissolved oxygen ranged from 79 to $84 \%$ of air saturation and gradually decreased toward the sediment.

\section{PCR-DGGE}

The PCR-DGGE analysis was performed to reveal vertical shifts in the bacterial 
community structure in the snow core (Fig. 2, lanes 1 to 6 ). The DGGE band patterns of the six sections (including sediment) were distinguishable from each other, but snow samples of adjacent layers exhibited similar band patterns. Band A was prominent in the deepest two layers of snow core $(0-20$ and $20-50 \mathrm{~cm})$, and related to methanotrophs of the class Gammaproteobacteria. Three DGGE bands, B, C, and D were detected from wide region of core, and all were related to the iron-reducing bacteria of the genus Geobacter. The banding pattern obtained from the 80-120 cm layer was characterized by two dominant bands, E and F, deriving from members of the phylum Bacteroidetes and the class Betaproteobacteria respectively. Band $G$ was specific for top layer of the core, and was derived from betaproteobacteria. The PCR-DGGE analysis was also performed on the samples obtained in 2005 (lane 8 and 9). Despite differences in sample type and DNA extraction methods, band patterns of samples obtained in 2005 were quite similar to each other. Almost all bands detected from snow samples of 2008 appeared in band pattern of samples collected in 2005, except for band B. There were several bands detected only from samples of 2005, including band $\mathrm{H}$ related to gammaproteobacterial methanotrophs.

\section{Cloning analyses}

The sample of precipitate obtained in 2005 was subjected to cloning analyses. From the clone library of bacterial 16S rDNA, 51 sequences were obtained and sorted into 20 OTUs. The closest relatives of the predominant OTUs are listed in Table 2 (also see Table S1 for the remaining OTUs). Twelve clones were affiliated with the phylum Bacteroidetes, half of which belonged to the OTU OZE-B3. The sequence of DGGE band E was almost identical to those of 4 clones belonging to the OZE-B3. Of the 13 OTUs, 38 clones belonged to the phylum Proteobacteria, including 23 beta-, 9 gamma-, and 6 deltaproteobacterial clones. The 
betaproteobacterial clones included those of 2 dominant OTUs, OZE-B9 and OZE-B11 (Table 2). Two clones of OZE-B11 had sequence identical to DGGE band F. The 9 gammaproteobacterial clones all fell within the cluster of methanotrophs and were related to Methylobacter species (Fig. 3). Two OTUs (OZE-B18 and OZE-B19) were recognized in this lineage and they corresponded to the DGGE bands $\mathrm{H}$ and $\mathrm{A}$, respectively. All the deltaproteobacterial clones were closely related to dissimilatory iron-reducing bacteria of the genus Geobacter (Fig. 3). Five deltaproteobacterial clones belonged to OTU named OZE-B1, and DGGE bands C and D corresponded to this OTU. The remaining clone was identified as a member of the candidate division OP11, and clones corresponding to DGGE bands B and G were not detected.

The 46 sequenced clones of eukaryotic SSU rDNA could be grouped into 33 OTUs (Table S2). One of the OTUs comprised approximately $11 \%$ of the library, and the remaining clones were less than $4.5 \%$ (2 clones or fewer). The most dominant OTU, OZE-E13, was closely related to Lacrymaria marina (Table S2). Several OTUs had close identified relatives, but none of them were closely related to known snow algae or other green algae.

In the RuBisCO gene analyses, clones closely related to sulfur oxidizers were frequently obtained from the libraries of both the forms. With the primer set targeting green-like form I, multiple OTUs related to Thiobacillus thioparus were detected, whose clones occupied a significant portion of the library (Fig. S2). Several OTUs related to oxygenic phototrophs were also detected. With regard to form II, the majority of the 44 sequenced clones were closely related to each other. They were also related to the sulfur-oxidizing proteobacteria Thiobacillus intermedius K12, Halothiobacillus sp. RA13, Halothiobacillus neapolitanus, and Thiobacillus denitrificans (Fig. S2).

From the clone library of pmoA genes, 14 clones were sequenced, all of which were closely 
related to each other and to Methylobacter species (Fig. 4).

\section{Discussion}

Colorings of snow caused by the blooming of snow algae have been reported in various regions, mainly in alpine regions and at higher latitudes [9]. The phenomenon investigated in this study resembles snow algal blooms in several ways, but is also clearly distinct from them. Although brown-colored snow contains particles resembling snow algae in size, the color of the particles is completely different from those of the known algae. In addition, accumulation of brown particles can be found in deeper layers of snow.

It has been demonstrated that a large amount of Fe accumulated on the surface of the particles, by electron-induced X-ray fluorescence [24]. Consistent with this, there was strong positive correlation between particle abundance and Fe amount (Table 1). Accumulation of total Fe within colored snow was shown in the previous study [24], but it has not been verified whether accumulated Fe is available for microbial respiration or not. In the present study, it was suggested that at least part of accumulated iron was microbially reducible, and amount of reducible forms was also considerable. The measured amounts of hydroxylamine-reducible iron would include Fe(III) generated by oxidization of Fe(II) during sample preparation. Contribution of Fe(II) can be estimated roughly from concentration of $\mathrm{Fe}(\mathrm{II})$ in interstitial water samples. The ratios of $\mathrm{Fe}(\mathrm{II})$ in interstitial water to the reducible Fe(III) in corresponding sections were less than 0.07, except for $20-50 \mathrm{~cm}$ layer. At the most heavily colored layer, the value was as high as 0.64 and it is strongly suggested that specific process involving iron compounds occurred in the colored layer. The result of DGGE analysis seemed to consistent with distribution of Fe compounds. From the layer where reducible Fe and Fe(II) were abundant, iron-reducing bacteria were detected as bands with high relative 
intensities (Fig 2, band B, C, D).

Although mechanism for iron accumulation has not been clarified yet, the source of iron is likely to be underlying soil. In the study field, it was reported that concentration of iron in stream water increased during snow-covered season, concomitantly with decrease of redox potential [17]. In that study, authors noted that anaerobic zone could have developped under snow, resulting from inhibition of gas exchange by accumulated snow [1] and microbial activities at temperature near the freezing point [2].

In general, it is difficult to deduce the functions of bacteria detected only as $16 \mathrm{~S}$ rDNA sequences. Such speculation can be accomplished when the obtained sequences fell within the specific phylogenetic cluster characterized by common physiological properties. In the cloning analysis of 16S rDNA, 4 OTUs of two lineages satisfied this requirement (Fig. 3). The first group of clones (the OTUs OZE-B18 and OZE-B19) fell within the cluster of the genus Methylobacter, supported with high bootstrap values. It is very probable that they utilize methane available in the snow as a carbon source. They were closely related to $M$. tundripaludum and M. psychrophilus, isolated from arctic areas [21], and this result is consistent with that of the pmoA gene analysis (Fig. 4). The other group of clones belonged to the Geobacter species cluster (Fig. 3), which are dissimilatory iron-reducing bacteria. These results support validity of discussion on DGGE bands and substance distributions, presented above.

The most frequently detected bacterial OTU was OZE-B9, and its closest cultivated relative was Rhodoferax ferrireducens (Table 2). This bacterium possesses psychrotolerance and Fe(III)-reducing ability [5], appropriate to the conditions in the iron-rich snow. Nevertheless, it is still unclear whether bacteria of OZE-B9 share any of these characteristics with $R$. ferrireducens since other species of this genus have considerably different physiological 
properties [5]. The other major bacterial OTUs, OZE-B3 and OZE-B11, were also detected by DGGE as band E and band F, respectively (Table 2). The relative intensities of these bands were especially high in 80-120 cm layer, characterized by low number of the brown particles (Fig. 2). Therefore, bacteria corresponding to these two OTUs would not be essential member of the community associated with the snow coloration.

In the cloning analysis of eukaryotic SSU rDNA, quite diverse organisms were detected (Table S2), but their roles in the coloring phenomenon could hardly be inferred. None of the obtained clones were related to snow algae, suggesting the absence of snow algal involvement in this phenomenon. Nevertheless, snow algae may have been undetected due to defects in the applied method depending on PCR. Since genomic DNA preparations were used as templates for PCR, amplification might have been interfered by the presence of introns. The primers used for the gene analysis of green-like form I RuBisCO have mismatches against snow algae, and thus are not suited to detect them.

In the gene analyses for the two forms of RuBisCO, both clone libraries were dominated by OTUs related to sulfur oxidizers; however, corresponding organisms were not identified in the $16 \mathrm{~S}$ rDNA clone library. Abundant Fe(II) in the colored snow potentially serve as electron donors, however, the results of this study were insufficient to specify the electron donors utilized by the detected autotrophs.

The main object of the present study was basic characterization of the remarkable snow coloration, and the obtained results specifically emphasized the uniqueness of this phenomenon. Although the SSU rDNA clone libraries were dominated by organisms of unspecified functions, iron reducers of the genus Geobacter were determined to be associated with this phenomenon. It is still uncertain, however, whether these organisms are the cause of snow coloration or secondary inhabitants. In addition, electron donor for iron reduction by 
these organsins has not been identified. Advanced investigations focusing on these points will be an effective approach to reveal the biogeochemical processes associated with this phenomenon, in relation to the environmental characteristics of snow coverage on wetlands.

\section{Acknowledgments}

The study site is the special area being protected in National Natural Park under the control of the Ministry of the Environment of Japan. Our study was done under the permission of related organizations. Our thanks to Oze Ringyou KK for keeping this area open and for permission to do our work, and to The Oze Preservation Foundation for providing various assistances. This work was done as one of series of projects sponsored by the Ministry of the Environment of Japan. We thank Kenta Yoshii for his assistance in sampling and chemical analysis. This study was supported partly by the Grant for Joint Research Program (2005) of the Institute of Low Temperature Science, Hokkaido University. This study was also supported by grants from the Ministry of Education, Culture, Sports, Science and Technology, Japan, to Kojima (19770008) and to Fukui (16370014).

\section{References}

[1] M. R. Albert, E.F. Shultz, Snow and firn properties and air-snow transport processes at Summit, Greenland, Atmos. Environ. 36 (2002) 2789-2797.

[2] M.H. Chantigny, D.A. Angers, P. Rochette, Fate of carbon and nitrogen from animal manure and crop residues in wet and cold soils, Soil Biol. Biochem. 34 (2002) 509-517.

[3] N.B. Dise, Winter fluxes of methane from Minnesota peatlands, Biogeochemistry 17 (1992) 71-83.

[4] H. Elsaied, T. Naganuma, Phylogenetic diversity of ribulose-1,5-bisphosphate 
carboxylase/oxygenase large-subunit genes from deep-sea microorganisms, Appl. Environ. Microbiol. 67 (2001) 1751-1765.

[5] K.T. Finneran, C.V. Johnsen, D.R. Lovley, Rhodoferax ferrireducens sp. nov., a psychrotolerant, facultatively anaerobic bacterium that oxidizes acetate with the reduction of Fe(III), Int. J. Syst. Evol. Microbiol. 53 (2003) 669-673.

[6] H. Fukuhara, A. Ohtaka, N. Kimura, M. Fukui, Y. Kikuchi, S. Nohara, M. Ochiai, Y. Yamamoto, Oze Akashibo Reserch Group, Spring red snow phenomenon 'Akashibo' in the Ozegahara mire, central Japan, with special reference to the distribution of invertebtates in red snow, Internat. Verein. Limnol. 28 (2002) 1645-1652.

[7] H.L. Gorton, W.E. Williams, T.C. Vogelmann, The light environment and cellular optics of the snow alga Chlamydomonas nivalis (Bauer) Wille., Photochem. Photobiol. 73 (2001) 611-620.

[8] T. Henckel, M. Friedrich, R. Conrad, Molecular analyses of the methane-oxidizing microbial community in rice field soil by targeting the genes of the 16S rRNA, particulate methane monooxygenase, and methanol dehydrogenase Appl. Environ. Microbiol. 65 (1999) 1980-1990.

[9] R.W. Hoham, B. Duval, Microbial ecology of snow and freshwater ice with emphasis on snow algae, In: H.G. Jones, J.W. Pomeroy, D.A. Walker, R.W. Hoham (Eds.) Snow Ecology: An Interdisciplinary Examination of Snow-covered Ecosystems, Cambridge University Press, Cambridge, 2001.

[10] A. Holmes, A. Costello, M. Lidstrom, J. Murrell, Evidence that particulate methane monooxygenase and ammonia monooxygenase may be evolutionarily related, FEMS Microbiol. Lett. 132 (1995) 203-208.

[11] S. Kumar, K. Tamura, I.B. Jakobsen, M. Nei, MEGA2: molecular evolutionary genetics 
analysis software, Bioinformatics 17 (2001) 1244-5124.

[12] C. Körner, Alpine Plant Life. Springer, Berlin, 1999.

[13] D.J. Lane, 16S/23S rRNA sequencing, In: E. Stackebrandt, M.Goodfellow (Eds.), Nucleic acid techniques in bacterial systematics, Wiley, New York, 1991

[14] D.R. Lovley, E.J. Phillips, Rapid assay for microbially reducible ferric iron in aquatic sediments, Appl. Environ. Microbiol. 53 (1987) 1536-1540.

[15] R.A. Melloh, P.M. Crill, Winter Methane Dynamics in a Temperate Peatland, Global Biogeochem. Cycles. 10 (1996) 247-254.

[16] G. Muyzer, T. Brinkhoff, U. Nübel, C. Santegoeds, H. Schafer, C. Wawer, Denaturing gradient gel electrophoresis (DGGE) in microbial ecology, In: A.D.L. Akkermans, J.D. van Elsas, F.J. de Bruijn (Eds.), Molecular Microbial Ecology Manual, 3rd ed. Kluwer Academic Publishers, Dordrecht, 1996.

[17] M. Seto, T. Akagi, Influence of snow on iron release from soil, Geochem. J. 39 (2005) $173-183$

[18] H. Tamura, K. Goto, T. Yotsuyanagi, M. Nagayama, Spectrophotomeric determination of iron(II) with 1,10-phenanthroline in the presence of large amount of iron(III), Talanta. 21 (1974) 314-318.

[19] J.D. Thompson, T.J. Gibson, F. Plewniak, F. Jeanmougin, D.G. Higgins, The ClustalX windows interface: Flexible strategies for multiple sequence alignment aided by quality analysis tools, Nucleic. Acids. Res. 24 (1997) 4876-4882.

[20] E.J. van Hannen, W. Mooij, M.P. van Agterveld, H.J. Gons, H.J. Laanbroek, Detritus-dependent development of the microbial community in an experimental system: qualitative analysis by denaturing gradient gel electrophoresis, Appl. Environ. Microbiol. 65 (1999) 2478-2484. 
[21] I. Wartiainen, A.G. Hestnes, I.R. McDonald, M.M. Svenning, Methylobacter tundripaludum sp. nov., a methaneoxidizing bacterium from Arctic wetland soil on the Svalbard islands, Norway (78 degrees N), Int. J. Syst. Evol. Microbiol. 56 (2006) 109-113.

[22] K.P. Wickland, R.G. Striegl, S.K. Schmidt, M.A. Mast, Methane flux in subalpine wetland and unsaturated soils in the southern Rocky Mountains, Global Biogeochem. Cycles. 13 (1999) 101-113.

[23] K. Wilson, Miniprep of bacterial genomic DNA, In: E.M. Ausubel, R. Brent, R.E. Kingston, D.D. Moore, J.G. Seidman, J.A. Smith, K. Struhl (Eds.) Short Protocols in Molecular Biology, 2nd ed. John Wiley and Sons, New York, 1990.

[24] Y. Yamamoto, A. Ohtaka, T. Hayashi, H. Fukuhara, S. Nohara, M. Ochiai, Spring red snow phenomenon caused by iron accumulated around algal spores in alpine mires in Japan, Verh. Internat. Verein. Limnol. 29 (2006) 1947-1950. 
Table 1. Vertical profiles of the brown particle abundance and chemical compound concentrations in accumulation of snow.

\begin{tabular}{ccc}
\hline Core & & \\
\hline Layer $(\mathrm{cm})^{\mathrm{a}}$ & ${\text { Particle }\left(10^{3} / \mathrm{ml}\right)^{\mathrm{b}}}$ & Hydroxylamine-reducible Fe $(\mu \mathrm{M})^{\mathrm{b}}$ \\
\hline $120-160$ & 4.2 & 16 \\
$80-120$ & 10 & 53 \\
$50-80$ & $\mathrm{ND}^{\mathrm{c}}$ & 102 \\
$20-50$ & 106 & 700 \\
$0-20$ & 29 & 149 \\
\hline
\end{tabular}

\begin{tabular}{cccc}
\hline Interstitial water & & & \\
\hline${\text { Depth }(\mathrm{cm})^{\mathrm{a}}}^{\mathrm{Fe}}(\mathrm{II})(\mu \mathrm{M})$ & $\mathrm{CH}_{4}(\mu \mathrm{M})$ & $\mathrm{O}_{2}(\mu \mathrm{M})$ \\
\hline 128 & 0.63 & 0.63 & 311 \\
93 & 2.7 & 2.0 & $\mathrm{ND}$ \\
58 & 6.8 & 4.4 & 307 \\
28 & 446 & 0.9 & 294 \\
3 & 6.4 & 3.1 & $\mathrm{ND}$ \\
\hline
\end{tabular}

a: distance from the sediment-snow interface.

b: based on volume of water resulting from melting snow.

c: ND, not determined.

*This table should be placed in Results. 
Table 2. Dominant OTUs in the clone library of bacterial SSU rDNA.

\begin{tabular}{|c|c|c|c|c|c|c|}
\hline OTU $^{a}$ & $\begin{array}{l}\text { No. of } \\
\text { clone }\end{array}$ & $\begin{array}{l}\text { Corresponding } \\
\text { DGGE band }{ }^{\mathrm{C}}\end{array}$ & Phylogenetic group & Closest cultivated relative $^{\mathrm{b}}$ (acc. no) & Identities & Accession number \\
\hline OZE-B1 & 5 & C, D & Deltaproteobacteria & Geobacter pelophilus (U96918) & $95 \%$ & AB504913-AB504917 \\
\hline OZE-B3 & 6 & $E$ & Bacteroidetes & Flavisolibacter ginsengisoli (AB267477) & $92 \%$ & AB504919-AB504924 \\
\hline OZE-B9 & 10 & - & Betaproteobacteria & Rhodoferax ferrireducens (СР000267) & $98 \%$ & AB504931-AB504940 \\
\hline OZE-B11 & 4 & $\mathrm{~F}$ & Betaproteobacteria & Paucibacter toxinivorans (AY515389) & $97 \%$ & AB504942-AB504945 \\
\hline OZE-B18 & 4 & $\mathrm{H}$ & Gammaproteobacteria & Methylobacter psychrophilus (AF152597) & $95 \%$ & AB504954-AB504957 \\
\hline OZE-B19 & 5 & A & Gammaproteobacteria & Methylobacter psychrophilus (AF152597) & $98 \%$ & AB504958-AB504962 \\
\hline
\end{tabular}

a: OTUs detected as more than 4 clones are shown (total number of clones analyzed was 51).

b: according to the results of BLAST search for representative clone of each OTU.

c: band name defined in Fig. 2.

*This table should be placed in Results. 


\section{Figure legends}

Figure 1. Photographs of colored snowfield and samples analyzed in this study. (a) Heavily colored snowfield photographed in May, 2001. (b) Surface of colored snow studded with small pools. (c) The precipitates in a pool. (d) Whole core sample obtained in 2008. (e) Colored region of the core sample. (f) Microphotograph of the brown particles contained in the snow samples. Bar indicates $20 \mu \mathrm{m}$.

Figure 2. DGGE band patterns of $16 \mathrm{~S}$ rDNA fragments obtained from the core sampes (lane 1 to 7) and two types samples obtained in 2005 (lane 8 and 9). Lane 1, sediment; lane 2, 0-20 cm; lane 3 and lane 7, 20-50 cm; lane 4, 50-80 cm; lane 5, 80-120 cm; lane 6, 120-160 cm; lane 8, colored snow obtained from snow surface; lane 9, precipitate subjected to cloning analyses.

Figure 3. Phylogenetic tree showing the affiliations of bacterial 16S rDNA OTUs identified as Gamma- and Deltaproteobacteria. This minimum evolution tree was constructed with nucleotide sequences of 1463 positions. Numbers on nodes are percentage values of 1000 bootstrap resampling. The names of OTUs defined in this study are prefixed with “OZE-B”.

Figure 4. Phylogenetic relationships of PmoA OTUs obtained in this study. The clones sharing more than 163 amino acid in 165 sites were grouped into the same OTU. This minimun evolution tree was constructed with 150 amino acid sites. For the OTUs with plural clones, the numbers of clones are presented in parentheses. Numbers on nodes are percentage values of 1000 bootstrap resampling (values larger than 50 are shown). The names of OTUs defined in this study are prefixed with "OZE-P" 
$\begin{array}{lllllllll}1 & 2 & 3 & 4 & 5 & 6 & 7 & 8 & 9\end{array}$

$\mathrm{H}$

At

G

B

E

$\mathrm{F}$

C

D 
$56\lceil$ OZE-B19 (5 clones)

$73-$ Methylobacter psychrophilus AF152597

$99-$ Methylobacter tundripaludum AJ414655 Methylobacter sp. T20 AF131868 OZE-B18 (4 clones)

79 Methylomicrobium pelagicum X72775 Methylobacter luteus AF304195

Methylomonas aurantiaca X72776

Methylosphaera hansonii U77533

Geobacter pelophilus U96918

84
Geobacter pelo
OZE-B1 (5 clones)

$100 \sqrt[58]{ }$ Geobacter metallireducens L07834

Geobacter bremensis U96917

$52 \quad$ Pelobacter propionicus X70954

$100-$ Geobacter chapelleii U41561 Geobacter psychrophilus strain P35 AY653549 OZE-B2 (1 clone) 
